\title{
A Clinical Audit on the Compliance of Ultrasound Users to the Standard Operating Procedure of Ultrasonography in a Private Radiologic Academy
}

\author{
Y. YULIAWATI ${ }^{1}$ AND R. (III) P. DIOSO ${ }^{2 *}$
}

\begin{abstract}
This clinical audit identified the compliance rate of ultrasound users to the standard operating procedures (SOP); and identified the factors that led to a compliance rate of ultrasound human users. The review was conducted for six days in a private radiologic academy in Indonesia. Only 23 subjects selected randomly were audited. Of the 23 participants, there were 11 males and 12 females. Of the 11 males, seven were compliant, and three were non-compliant. Of the 12 females, eight were compliant, and four were non-compliant. The factors that affect the compliance to the SOP were based on the skills of the participants. Another factor identified was the way the standard operating procedure communicated to the human users on how to perform the ultrasound. Further training was therefore planned.
\end{abstract}

Key words: Clinical audit; ultrasonography; standard operating procedure; ultrasound among students; radiography; SOP on ultrasound

The standard operating procedure (SOP) for the use of ultrasonography found on Table 1 is audited. The review is conducted in a private radiologic academy in Indonesia. The authors are the auditors.

Furthermore, this audit seeks to: (1) identify the compliance rate of ultrasound users in demonstrating the SOP and (2) identify factors that led to compliance of human users to the SOP of ultrasonography.

It is also best to introduce ultrasonography having it done at primary referral centres where patients referred from primary health care for diagnostic examination (Dorland 1988). To introduce further, the use of ultrasound in performing and examining human bodies have potential risks, and benefits, particularly in the field of medicine (Dorland 1988; Chan 2009). Medical diagnostic ultrasound is an imaging modality that makes images showing slices of the body, or so-called tomographic images $($ tomo $=$ Gr. tome, to cut and graphic $=$ Gr. graphein, to write) (Dorland 1988; Chan 2009; Kossoff 2000). It is a diagnostic modality, as it gathers information about the biological medium (Dorland 1988). Also, medical ultrasonography uses high-frequency sound (in the megahertz [mHz] ranging millions of cycles per second/s) (Kossoff 2000).

Therefore, clinical audit on the use of ultrasound equipment is important to avoid errors (Patel 2010) in the operation of ultrasonography in diagnosing patients. Errors in ultrasonography may compromise diagnostic investigations. Also, the audit is an effort to improve service quality, therefore evaluating audit on the implementation of human comfort and safety (patient safety), the experiences of human users and the effectiveness of service delivery must be identified (Patel 2010).

\footnotetext{
${ }^{1}$ ATRO Persada Nusantara, Indonesia

${ }^{2}$ Faculty of Nursing, Lincoln University College, Malaysia

* Corresponding author (e-mail: duke@lincoln.edu.my)
} 
Table 1. Standard operating procedure for the use of ultrasonography.

\begin{tabular}{|c|c|c|c|c|c|}
\hline \multirow[t]{3}{*}{$\begin{array}{l}\text { ATRO PERSADA } \\
\text { NUSANTARA }\end{array}$} & \multicolumn{5}{|c|}{ STANDARD OPERATING PROCEDURE (SOP) } \\
\hline & \multicolumn{5}{|c|}{ ULTRASONOGRAPHY } \\
\hline & \multicolumn{2}{|c|}{$\begin{array}{l}\text { DOCUMENT NUMBER: } \\
\text { 110/ATRO.PN/SOP/2011 }\end{array}$} & \multicolumn{3}{|c|}{$\begin{array}{l}\text { AUDIT REF NUMBER } \\
16-06-X X-X X\end{array}$} \\
\hline \multirow[t]{2}{*}{ Verified by: } & \multirow{2}{*}{$\begin{array}{l}\text { Date Issued: } \\
01 \text { MARCH } 2011 \\
\text { Effective Date: } \\
01 \text { April } 2011 \\
\end{array}$} & \multicolumn{4}{|c|}{ Name of the person being audited: } \\
\hline & & \multicolumn{4}{|c|}{ Identification number: } \\
\hline AUDITOR NAME(s) & \multicolumn{5}{|l|}{$\operatorname{xxxxxxxx}$} \\
\hline \multicolumn{6}{|c|}{$\begin{array}{l}\text { 1. Demonstrate the proper t } \\
\text { 2. Perform the standard ope }\end{array}$} \\
\hline \multicolumn{6}{|c|}{$\begin{array}{l}\text { Policy: ATRO Persada Nusantara Bekasi No. 99/ATRO.PN/SK/I/2011 for maintenance of medical- } \\
\text { based devices. } \\
\text { Note: only less than } 99 \text { human users will be scheduled for auditing, on a daily basis. }\end{array}$} \\
\hline \multicolumn{4}{|l|}{ Operating Procedure(s) } & Done & $\begin{array}{l}\text { Not } \\
\text { done }\end{array}$ \\
\hline \multicolumn{4}{|c|}{$\begin{array}{l}\text { 1. Connect the stabilizer cables to a power source, and wait for the signal to } \\
\text { flash on screen }\end{array}$} & & \\
\hline \multicolumn{4}{|c|}{$\begin{array}{l}\text { 2. Ensure that a requisition/s is/are provided; if in the case of emergency, } \\
\text { ensure that ultrasonography reference number is documented as } \\
\text { "emergency." }\end{array}$} & & \\
\hline \multicolumn{4}{|c|}{$\begin{array}{l}\text { 3. Select the type of examination to be used or press automatic selection }(20 \mathrm{~Hz} \\
\text { to } 20 \mathrm{kHz} \text { or } 1 \mathrm{MHz} \text { and } 20 \mathrm{MHz})\end{array}$} & & \\
\hline \multicolumn{4}{|c|}{$\begin{array}{l}\text { 4. Check the patient, or see if the desired object from the body is ready for } \\
\text { shooting while placing the acoustic gel on the hand-held transducer }\end{array}$} & & \\
\hline \multicolumn{4}{|c|}{$\begin{array}{l}\text { 5. Double check the button freeze if functioning; a trial capture is a must to test } \\
\text { the frequencies and acoustic impedance }\end{array}$} & & \\
\hline \multicolumn{4}{|c|}{$\begin{array}{l}\text { 6. If the image needs to be printed, the printer must be turned on, and the } \\
\text { ultrasound must be connected with the stretcher-printer device }\end{array}$} & & \\
\hline \multicolumn{4}{|c|}{$\begin{array}{l}\text { 7. Verify, quality of the picture if it requires being repeated; repeat as it deems } \\
\text { necessary and print again }\end{array}$} & & \\
\hline \multicolumn{4}{|c|}{ 8. Turn off the machine and clean } & & \\
\hline \multicolumn{4}{|c|}{ 9. Unplug the stabilizer if it is still connected } & & \\
\hline \multicolumn{4}{|c|}{ 10. Ensure patient comfort, and label the ultrasound result } & & \\
\hline \multicolumn{6}{|l|}{ Remarks: } \\
\hline
\end{tabular}




\section{BACKGROUND}

Ultrasound is used for more than 20 decades (Dorland 1988; Masic et al. 2010; Fine 1989; Gautschi 2002; Dalecki 2004; Krautkrämer \& Krautkrämer 1990). Ultrasound has lesser complications, and it is safer for humans to use as compared to any other radioactive diagnostic investigation devices (Dorland 1988; Chan 2009; Kossoff 2000).

Ultrasonography has a sound wave with a frequency above the audible range from $20 \mathrm{~Hz}$ to $20 \mathrm{kHz}$ (Patel 2010). If the sound is a mechanical energy that needs a medium to propagate (Masic et al. 2010; Fine 1989; Gautschi 2002; Dalecki 2004), it cannot travel in vacuum (Krautkrämer \& Krautkrämer 1990). That is why the ultrasound machine is designed. The ultrasound machine generates the sound that first acts as a loudspeaker are sending out an acoustic pulse in a given direction (Masic et al. 2010). The acoustic pulse then echoes along the paths which are emitted by the ultrasound machine (Kossoff 2000). Thus carry information such as the images of the tissues and organs (Krautkrämer \& Krautkrämer 1990). However, humans can only hear echoes in the range of about 30 to 20000 cycles per second, and therefore cannot listen to the echoes of the ultrasound (Chan 2009). The sound frequencies of ultrasound machines are usually between $1 \mathrm{MHz}$ and $20 \mathrm{MHz}$, impossible for humans to hear (Kossoff 2000; Krautkrämer \& Krautkrämer 1990).

Ultrasounds also have the advantage of being real-time rather than static and can display not only image but live blood flow as information useful in a diagnostic examination (Dalecki 2004). Besides, it is possible to perform therapeutic procedures with the guidance of an ultrasound machine (Chan 2009).

\section{LITERATUR REVIEW}

The review of literature is necessary to validate the credibility of the SOP that was audited.

This section is further divided into: (1) the principle of ultrasonography; and (2) transducer's reflected echoes.

\section{The Principle of Ultrasound}

There are three components of ultrasonography (Kossoff 2000; Gautschi 2002; Dalecki 2004; Krautkrämer \& Krautkrämer 1990; Baun 2004). First, the transducers, to stream sound waves and receive the reflection and change acoustic waves into electronic signals (Baun 2004). Second, the monitor, functioning to conjure images (Baun 2004). Lastly, an ultrasound machine itself which serves to change the reflected sound waves into images flashed on a monitor (Baun 2004).

The ultrasound machine as the last component has a radiation that is believed to be the less dangerous (Dalecki 2004; Baun 2004). Because the diagnostic imaging uses a magnetic field, radio-frequency, and a computer to produce images of the pieces of the cross section of the human body, a minuscule amount of rads are emitted (Palmer 2002).

The monitor, which is the easiest component, as it converts electrical pulses amplified and further shown in the form of light from the oscilloscope screen (Baun 2004). The data obtained are then processed in the monitor as images printed out in the shape of photographs (Dorland 1988; Baun 2004).

Primarily, a hand-held probe called a transducer is placed directly on and moved over the human body to acquire the image (Gautschi 
2002). The acoustic gel is used to couple the probe to the body because the high-frequency sound waves do not travel well through the air (Masic et al. 2010).

The emission of acoustic energy and the recording of the echoes take place at the same time and recorded (the detectors) on the opposite side of the body (Cutnell, \& Jhonson 1998). The amount of echo returned after hitting a tissue interface is determined by a tissue property called acoustic impedance (Dorland 1988; Cutnell \& Jhonson 1998). This is an intrinsic physical property of a medium defined as the density of the medium times the velocity of wave propagation in the medium (Masic et al. 2010; Fine 1989; Cutnell \& Jhonson 1998). Sample organs and their acoustic impedance nonresidents in Table 2. bone or the lung generate very strong echoes due to a large acoustic impedance gradient (Kossoff 2000; Cutnell \& Jhonson 1998).

\section{Transducers' Reflected Echoes}

The resulting picture of the ultrasound from the transducer is to utilize the reflected echo of the ultrasonic waves when transmitted to a particular tissue or organ (Fine 1989). Echo of the waves is then detected by the transducer which converts acoustic waves into electronic signals to be processed and reconstructed into an image (Gautschi 2002). The development of ultrasonic transducers with excellent resolution capability, followed by the rapid advancement of digital computer technology and its supporting software, makes digital image processing possible (Dalecki 2004; Krautkrämer \& Krautkrämer 1990).

Table 2. Acoustic impedances of different body tissues and organs

(Dorland 1988; Kossoff 2000; Cutnell \& Jhonson 1998).

\begin{tabular}{c|c}
\hline Body tissue & Acoustic impedance in Rayls unit \\
\hline Alveoli & 0.0004 \\
Lung lobes & 0.18 \\
Peritoneum & 1.34 \\
Liver & 1.65 \\
Blood fluids & 1.65 \\
Kidney & 1.63 \\
Muscle & 1.71 \\
Bone & 7.8 \\
\hline
\end{tabular}

The intensity of a reflected echo is proportional to the difference (or mismatch) in acoustic impedances between two mediums (Masic et al. 2010). If two tissues have identical acoustic impedance, no echo is generated (Dalecki 2004). Interfaces between soft tissues of similar acoustic impedances usually produce low-intensity echoes (Cutnell \& Jhonson 1998). Conversely, interfaces between soft tissue and

\section{METHODOLOGY}

Before audit commences, the use of ultrasound was evaluated. Participants were then selected randomly, who were laboratory instructors and students of the radiography course. Participants were selected on-the-spot while demonstrating the use of ultrasound in the academy. 
The auditors ensured that the audit was approved by the Dean of the academy to be issued to the head of the laboratory. The auditors also ensured that the participants selected, autonomously allowed the auditors to observe them while demonstrating their skills on how to use the ultrasound.

The audit was conducted for six days. Only five subjects were audited per day. A total of 23 human users were audited.

The auditors prepared the checklist found on Table 1 and the written consent for the subjects to be signed, and filed in a portfolio with reference numbers. The participants were called one by one, in turn, to carry out the operation of the ultrasound and were observed using the checklist (Table 1).

Subjects or participants who could demonstrate the SOP of ultrasonography were categorized as compliant while non-compliant participants for those who could not perform the steps.

\section{FINDINGS}

Twenty-three participants consented to be audited (Table 3). There were 13 residents (Jakarta) who complied while ten did not $(13 / 10)$ as tabulated in Table 3. While the noncompliant were 10 being non-local residents of
Jakarta while 13 did not (10/13). The picture found on Figure 1 compared compliance and non-compliance.

Data showed that the audit results had identified more compliant participants.

The indicated reliability of the estimate was set at $95 \%$ confidence interval (CI). The standard deviation $(\sigma)$ to perfect compliance was found to be 2.64, which described the tightness of the clustering of compliant human users with a mean of 9.5. Of the 23 participants, it was likely probable to have $65 \%$ compliance $(\mathrm{p}=0.0005847)$.

For the non-compliant, a $\sigma=4.79$ with a mean of 7.5 was identified. The clustering was not too much tight, and therefore noncompliance to the standard operating procedure can easily be avoided. The $p=0.04946$, described confidently that there were only $35 \%$ of the 23 human users who were non-compliant.

The figure further identified compliance, where participants could get the hepatic object well. While the non-compliance showed a mistake that was full of whitish discolouration of the hepatic object. This whitish discolouration occurred because the setting of the time gain control was not properly adjusted and calibrated when the participants shot the object using the ultrasonography.

Table 3. Result the audit ultrasonography in a private academy.

\begin{tabular}{c|ccccccc}
\hline Categories & Male & Female & Jakarta & Non Jakarta & Mean & $\sigma$ & $\begin{array}{c}\mathrm{p}= \\
@ 95 \% \mathrm{CI}\end{array}$ \\
\hline Compliance & 7 & 8 & 13 & 10 & 9.5 & 2.64 & 0.0005847 \\
Non-compliance & 3 & 4 & 10 & 13 & 7.5 & 4.79 & 0.04946 \\
\hline
\end{tabular}




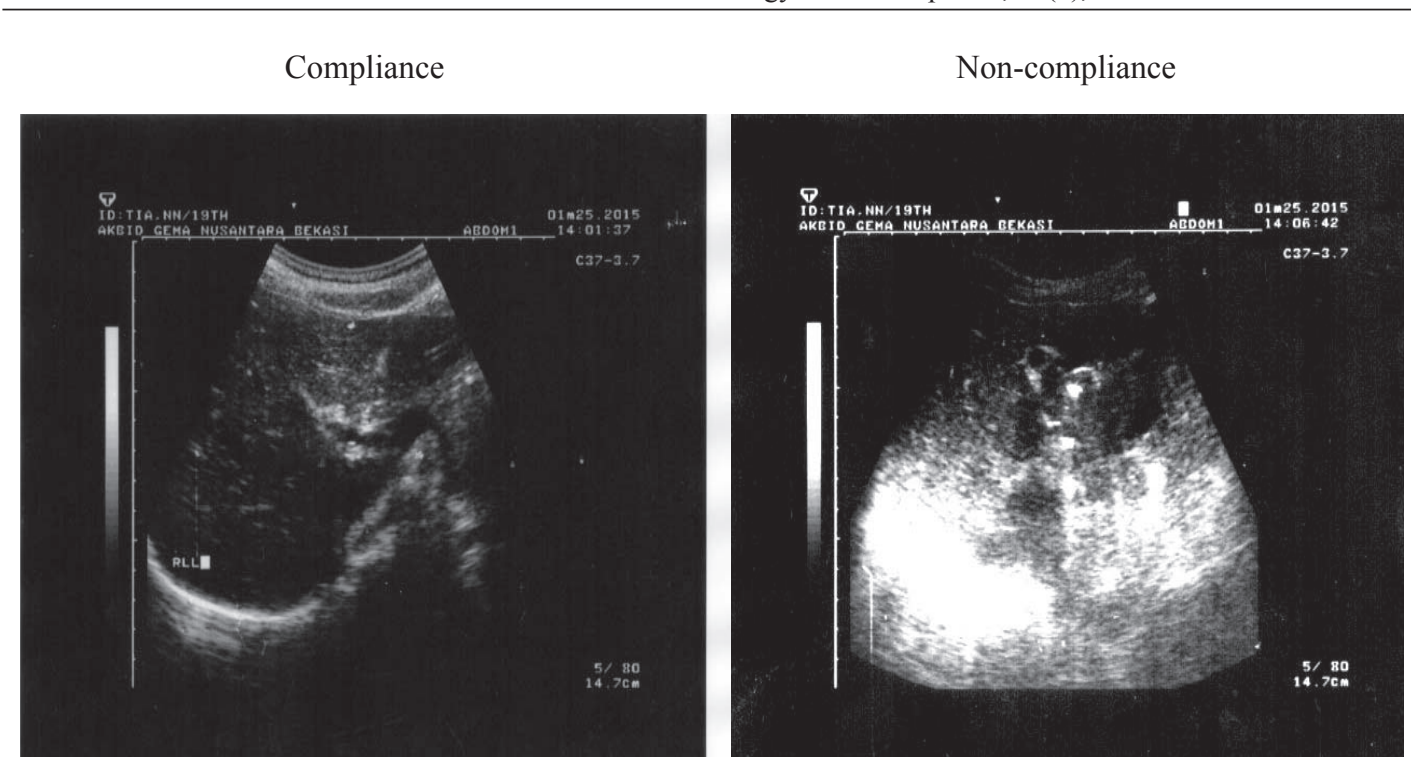

Figure 1. Identifying compliance and non-compliance.

One of the factors identified was the improper use of the transducers. Most of the participants audited did not demonstrate skills in dexterity. Skills in performing the steps should be practiced. Since the ultrasound users were still a novice, the demonstration of the use of ultrasound was not done using the proper techniques. Another factor identified was the communication skills of the ultrasound machine users to the provided with procedure manuals written in English. Since there were language barriers, the users misunderstood the written manuals thus making the steps confusing. Furthermore, there were ultrasound users that were not trained well in reading the English language and were confused with the steps of the standard operating procedure. Those who did not practice in Central Hospitals which were affiliated with the Academy who were non-compliant, might have experienced barriers in the written operating system.

\section{ACTION PLAN FOR CHANGE MANAGEMENT}

The selected private academy that prepared skilled radiographer should be able to master their radiographic technique and also be able to operate ultrasound equipment anticipated to be practiced in the hospital setting. This was the primary plan of the authors that was why the SOP was developed.

Secondly, planning on how to communicate the language of the SOP was to be addressed to enhance the change management. Handbooks might be an action plan to improve the communication process, and it must be written in the national language of Indonesia and English as well. This manual must have a high level of competence relating to student skills.

Thirdly, there should be education and training on the use of ultrasound equipment. Training was for participants to be proficient in the skills of using the cutting-edge technology of ultrasonography.

The plan to use the SOP in the laboratory and the use of ultrasound should be implemented within a year. Where the results would be followed up by the director if necessary so 
to make changes to the existing SOP and for its further development should be done semiannually. The SOP would then be submitted to the relevant heads and disseminated throughout the academy within a month.

It was important for all participants to know how to use ultrasound within a year. Planning to practice in the laboratory of the Academy before facing the real patients should be done monthly to avoid the pitfalls of the training provided before going to the hospitals. It was anticipated that those who attended the seminars and training would disseminate the information and their knowledge of the SOP to those who used the laboratory as their workplaces.

The use of the SOP for the utilization of the ultrasound would be identified as a potential threat to the success of the change process if they do not comply. Therefore, a continuous audit should always be done every six months to freeze the change process (Table 4).

\section{CONCLUSION}

Of the 23 participants, there were 11 males and 12 females identified. Of the 11 males, seven were compliant $(65 \%)$, and three were noncompliant (35\%). Of the 12 females, eight were compliant (65\%), and four were non-compliant (35\%) participants. It was also identified that the non-compliant participants used the transducers incorrectly. This is tailored to the type of examination identified, that the object to be inspected using the ultrasound, and pieces or slices in shooting and shooting techniques to produce optimal pictures were not properly demonstrated because of the incorrect use of the transducers.

Therefore, it was identified that the factors that affect the compliance to the standard operating procedures were based on the skills of the participants. Another factor identified was the manner of communication to the human users on how to use the ultrasound. Lack of further training was also designated as an element and is therefore planned.

Table 4. The continuous semi-annual auditing tool.

\begin{tabular}{|c|c|c|}
\hline $\begin{array}{c}\text { What we want them to do } \\
\text { (Standard operating } \\
\text { procedure) }\end{array}$ & $\begin{array}{c}\text { What they are doing } \\
\text { (Action plan) } \\
\text { (Findings) }\end{array}$ \\
$\begin{array}{c}\text { Using Standard Operational } \\
\text { Procedure Ultrasound } \\
\text { Step in the use of the machine } \\
\text { Ultrasound }\end{array}$ & $\square$ Complied $\square$ Not Complied & $\begin{array}{c}\text { Read the handbooks } \\
\text { and attend seminars }\end{array}$ \\
& &
\end{tabular}


Date of submission: August 2016

Date of acceptance: November 2016

\section{REFERENCES}

Baun, J 2004, Physical principles of general and vascular sonography, Chap 8, San Fransisco, California, USA.

Chan, VWS 2009, Ultrasound imaging for regional anesthesia, 2 nd edn, Toronto, $\mathrm{ON}$, Toronto Printing Company.

Cutnell, JD \& Kenneth, W Jhonson, KW 1998, Physics (frequency range of human hearing), 4th edn, Wiley, New York, pp. 466.

Dalecki, D 2004, 'Mechanical bioeffects of ultrasound', Annu. Rev. Biomed. Eng., vol. 6, pp. 229-48.

Dorland, NW 1988, Dorland's illustrated medical dictionary, 27th edn, W.B. Saunders Co., Philadelphia, PA, USA.

Fine, MJ 1989, Introduction to ultrasound imaging, Interson Corporation Parkway, Pleasanton, USA.
Gautschi, G 2002, Piezoelectric sensorics: force, strain, pressure, acceleration and acoustic emission sensors, material and amplifiers, Springer.doi:10.1007/978-3-6620473-3. ISBN 978-3-662-04732-3.

Kossoff, G 2002, 'Basic physics and imaging characteristics of ultrasound', World J. Surg., vol. 24, pp. 134-142.

Krautkrämer, J \& Krautkrämer, H 1990, Ultrasonic testing of materials, 4th edn, Springer.

Masic, I, Ridjanovic, Z \& Pandza HM 2010, 'Medical informatics', Avicena, Sarajevo, pp. 416-430.

Palmer, PES 2002, Manual of diagnostic ultrasound, University of California Davis, California, USA.

Patel, S 2010, 'Achieving quality assurance through clinical audit', Nursing Management, vol. 17, no. 3, pp. 1-19. 